\title{
Key bacterial, fungal, and protist taxa regulate nutrient availability during vegetation restoration under different climate conditions in karst soil
}

\author{
Dan Xiao ${ }^{1}$, Xunyang $\mathrm{He}^{1}$, Wei Zhang ${ }^{2}$, Peilei $\mathrm{Hu}^{3}$, Mingming $\mathrm{Sun}^{4}$, and Kelin Wang ${ }^{2}$ \\ ${ }^{1}$ Institute of Subtropical Agriculture, Chinese Academy of Sciences, Changsha 410125, \\ China \\ ${ }^{2}$ Institute of Subtropical Agriculture, Chinese Academy of Sciences \\ ${ }^{3}$ Institute of Subtropical Agriculture, Chinese Academy of Sciences, Changsha 410125, \\ China \\ ${ }^{4}$ Huazhong Agricultural University, Wuhan, 430070, China
}

September 26, 2021

\begin{abstract}
To determine the mechanisms underlying the response of microbial interactions to vegetation restoration under different climate conditions, we examined the changes occurring at two temperature levels in soil bacterial, fungal, and protist microbiomes under a reference cropland and a plantation forest and a shrubland. Bacterial and protist diversity levels in the high-temperature region of Guangxi $\left(20.9^{\circ} \mathrm{C}\right)$ were higher in cropland than in shrubland or plantation forest. By contrast, fungal richness was lower under cropland than shrubland. The bacterial phyla Cyanobacteria, Gemmatimonadetes, and Nitrospirae, the fungal taxa Ascomycota and Mucoromycota, and the protist groups Ciliophora, Lobosa, and Ochrophyta had lower abundance under vegetation restoration than cropland. There were no significant differences between shrubland and plantation forest in terms of bacterial, fungal, or protist diversity or community composition. A co-occurrence network revealed higher numbers of correlated links among bacterial, fungal, and protist taxa in the low-temperature region of Guizhou $\left(14.6{ }^{\circ} \mathrm{C}\right)$ than Guangxi. Stronger interactions were observed among microbial taxa under cropland than under vegetation restoration. Protist groups Cercozoa and Lobosa showed the highest numbers of links with bacterial phyla Acidobacteria and Proteobacteria and with fungal phylum Ascomycota. Hence, a strong food web existed among these microbiomes. Proteobacteria, Acidobacteria, Ascomycota, and Cercozoa were correlated with soil nutrient levels. Therefore, these dominant taxa determined nutrient availability. The predation of bacteria and fungi by protists was more intense at low temperature than high temperature. Key bacterial, fungal, and protist groups, their co-occurrence networks, and environmental temperature influence soil nutrient accumulation during vegetation restoration.
\end{abstract}

\section{Key bacterial, fungal, and protist taxa regulate nutrient} availability during vegetation restoration under different climate conditions in karst soil

\footnotetext{
Dan Xiao ${ }^{1,2, \#}$, Xunyang $\mathrm{He}^{1,2, \#}$, Wei Zhang ${ }^{1,2^{*}}$, Peilei $\mathrm{Hu}^{1,2}$, Mingming Sun ${ }^{2,3}$, and Kelin Wang ${ }^{1,2^{*}}$

${ }^{1}$ Key Laboratory of Agro-ecological Processes in Subtropical Region, Institute of Subtropical Agriculture, Chinese Academy of Sciences, Changsha 410125, China

${ }^{2}$ Huanjiang Observation and Research Station for Karst Ecosystems, Chinese Academy of Sciences, Huanjiang 547100, China
} 
${ }^{3}$ College of Resources and Environment, Huazhong Agricultural University, Wuhan, 430070, China

\# These authors contributed equally to the manuscript.

${ }^{*}$ Corresponding author:

Wei Zhang (E-mail: zhangw@isa.ac.cn ; Tel: 86-0731-84619720; Fax: 86-0731-84612685) and Kelin Wang (E-mail:kelin@isa.ac.cn ; Tel: 86-0731-84615201; Fax: 86-0731-84612685)

Key Laboratory of Agro-ecological Processes in Subtropical Region, Institute of Subtropical Agriculture, Chinese Academy of Sciences, Changsha 410125, China

\begin{abstract}
To determine the mechanisms underlying the response of microbial interactions to vegetation restoration under different climate conditions, we examined the changes occurring at two temperature levels in soil bacterial, fungal, and protist microbiomes under a reference cropland and a plantation forest and a shrubland. Bacterial and protist diversity levels in the high-temperature region of Guangxi $\left(20.9{ }^{\circ} \mathrm{C}\right)$ were higher in cropland than in shrubland or plantation forest. By contrast, fungal richness was lower under cropland than shrubland. The bacterial phyla Cyanobacteria, Gemmatimonadetes, and Nitrospirae, the fungal taxa Ascomycota and Mucoromycota, and the protist groups Ciliophora, Lobosa, and Ochrophyta had lower abundance under vegetation restoration than cropland. There were no significant differences between shrubland and plantation forest in terms of bacterial, fungal, or protist diversity or community composition. A co-occurrence network revealed higher numbers of correlated links among bacterial, fungal, and protist taxa in the low-temperature region of Guizhou $\left(14.6^{\circ} \mathrm{C}\right)$ than Guangxi. Stronger interactions were observed among microbial taxa under cropland than under vegetation restoration. Protist groups Cercozoa and Lobosa showed the highest numbers of links with bacterial phyla Acidobacteria and Proteobacteria and with fungal phylum Ascomycota. Hence, a strong food web existed among these microbiomes. Proteobacteria, Acidobacteria, Ascomycota, and Cercozoa were correlated with soil nutrient levels. Therefore, these dominant taxa determined nutrient availability. The predation of bacteria and fungi by protists was more intense at low temperature than high temperature. Key bacterial, fungal, and protist groups, their co-occurrence networks, and environmental temperature influence soil nutrient accumulation during vegetation restoration.
\end{abstract}

\title{
Keywords :
}

Climate level, Co-occurrence network, Karst ecosystem, Soil nutrient, Vegetation type

\section{INTRODUCTION}

Soil microbes are the key drivers in nutrient cycling and storage, which in turn, determine ecosystem stability. Microbial diversity and community composition are affected by soil nutrient availability, vegetation type, and climate conditions (Fan et al., 2020; Liu et al., 2019a; Waldrop et al., 2006). Global warming and rainfall strongly influence plant growth and substrate properties and influence atmospheric carbon $(\mathrm{C})$ and nitrogen (N) dynamics (such as $\mathrm{CO}_{2}$ and $\mathrm{N}_{2} \mathrm{O}$ flux) by increasing microbial activity (Crowther et al., 2019; Talukder et al., 2021). Understanding the mechanism by which microorganisms respond to temperature and precipitation during vegetation restoration is vital for predicting soil nutrient maintenance and the effects of global climate change on it.

Bacteria, fungi, and protists play fundamental roles in regulating soil nutrient cycling. Bacterial and fungal taxa utilize different substrates (Schneider et al., 2012; van der Wal et al., 2013). Most bacterial groups such as the Proteobacteria and Actinobacteria prefer abundant resources (Baldrian et al., 2012; Fierer et al., 2012; Schneider et al., 2012). However, certain oligotrophs such as the Acidobacteria adapt to poor nutrient environments such as low $\mathrm{C}$ content (Ai et al., 2015). Compared to bacteria, fungi can tolerate extreme environments. Ascomycota and the Basidiomycota degrade recalcitrant carbon (van der Wal et al., 2013). Thus, the functions of bacteria and fungi differ under rich and limiting nutrient conditions. Protists directly consume bacteria and fungi under limiting available sources and play a key role in soil food web stability (Geisen et al., 2018, 2021). Consequently, bacterial and fungal population sizes and community compositions 
are modified by protists, which therefore, indirectly affect nutrient availability (Geisen et al., 2018). Previous studies focused on the impact of bacterial and fungal abundance and diversity on soil nutrient cycling (Lian et al., 2017; Xiao et al., 2017). However, the potential interactions among bacteria, fungi, and protists in cooccurrence networks and changes in soil nutrient $(\mathrm{C}, \mathrm{N}$, and $\mathrm{P})$ levels are poorly understood. Co-occurrence patterns may involve biotic interactions (Kara et al., 2013). Vegetation restoration and climate conditions are key factors determining soil C, N, and P availability. Hence, they indirectly affect soil microbial communities. For this reason, it is useful and informative to explore the microbiological mechanisms controlling soil nutrient levels under various vegetation types and climate conditions.

Variations in the soil nutrients exploited by microbial communities are influenced by vegetation type, temperature, and precipitation. Plant diversity increases when cropland is converted to vegetation restoration. There are numerous plant species under natural vegetation restoration as opposed to a single species under managed vegetation restoration (Hu et al., 2020; Ladygina et al., 2010; Lan and Sediments, 2021). High plant diversity increases nutrient (and especially organic $\mathrm{C}$ ) levels through litter input and root exudates. In this manner, it induces microbial growth and alters microbial community composition (Liu et al., 2008; MelladoVázquez et al., 2016). Temperature and precipitation directly and indirectly affect microbial communities. Low temperature and precipitation levels limit microbial growth (Pettersson and Båăth, 2003; Pietikainen et al., 2005; Stefan et al., 2014; Zhou et al., 2012). By contrast, elevated temperature and precipitation stimulate plant growth and root exudation, thereby indirectly enhancing microbial activity (Zhou et al., 2012). Climate level and vegetation type can influence microbial communities. Nevertheless, it is uncertain whether bacterial, fungal, or protist communities differ under natural and managed vegetation restoration on calcareous (alkaline karst) soils in response to climate change.

The karst region is distributed across southwestern China and covers an area of about 550,000 $\mathrm{km}^{2}$ (Jiang et al., 2014). Karst ecosystems are fragile; their substrate consists of shallow, discontinuous soil (Liu et al., 2019b; Wang et al., 2019). However, human population pressure forced agricultural expansion through the twentieth century and rapidly degraded the land in this region (Wang et al., 2019; Wen et al., 2016). Soil nutrient (organic $\mathrm{C}$ and total $\mathrm{N}$ ) loss occurs more rapidly in karst than non-karst ecosystems when the forest is anthropogenically converted to cultivation (Chen et al., 2012; Li et al., 2021; Zhang et al., 2013). Several ecological restoration projects such as the 'Grain-for-Green' project were implemented to restore and reconstruct vegetation in karst regions (Wang et al., 2004; Wang et al., 2019). Natural and artificial vegetation restoration measures were then widely promoted in these areas (Hu et al., 2018; Li et al., 2021; Wang et al., 2019). Understanding the mechanism underlying the response of microorganisms to different restoration measures in karst region contributes to nutrient accumulation and ecosystem stability. Soil $\mathrm{pH}$ was the key factor determining microbial community composition there. The relatively high $\mathrm{pH}$ and Ca content characteristic of karst soil suggest that its microbial diversity and community composition differ from those of non-karst soils in response to vegetation restoration (Hu et al., 2021; Lan and Sediments, 2021). However, it is unknown how bacteria, fungi, protists, and their interactions regulate nutrient availability in calcareous soils during vegetation restoration especially in response to changes in temperature and precipitation.

We selected plantation forest, a shrubland, and a cropland in the karst region and compared their soil properties and microbial (bacterial, fungal, and protist) profiles under two different climate conditions. The aims of this study were to 1) identify the key factors contributing to changes in bacterial, fungal, and protist diversity and community composition, 2) elucidate the interactive relationships among bacterial, fungal, and protist groups, and 3) determine the key microbiome controllers under natural and managed vegetation restoration and different climate conditions. We hypothesized that 1) bacterial, fungal, and protist community compositions differ between cropland and natural and managed vegetation restoration as microbial diversity is relatively higher under natural than managed vegetation restoration, and 2) the associations among bacterial, fungal, and protist groups are stronger under high temperature and precipitation than they are under conditions of low temperature and precipitation. 


\section{MATERIALS AND METHODS}

\subsection{Site selection and soil collection}

Field sampling was conducted in Guizhou Province and the Guangxi Autonomous Region of southwestern China. The spatial range was $104^{\circ} 82^{\prime}-108 \operatorname{deg} 37^{\prime} \mathrm{E}, 22 \operatorname{deg} 42^{\prime}-27 \mathrm{deg} 53$ 'N (Fig. 1). The soil type was calcareous lithosols (limestone soil) according to the Soil Taxonomy of China and the FAO/UNESCO system of soil classification. Samples were collected across six counties from typical karst regions with plantation forest $(\mathrm{PF})$, shrubland $(\mathrm{SH})$, and reference cropland $(\mathrm{CR})$. Plantation forest and shrubland comprised artificial and natural vegetation restoration, respectively, and cultivation was abandoned there in 2002-2003. Shuicheng, Jinsha, and Duyun counties are in Guizhou Province and Huanjiang, Mashan, and Longzhou counties are in Guangxi Autonomous Region. The mean annual temperatures (MAT) within the Guizhou and Guangxi sampling sites were $14.6 \operatorname{deg} \mathrm{C}$ and $20.9 \mathrm{degC}$, respectively. The mean annual precipitation (MAP) levels in Guizhou and Guangxi were 1,100 $\mathrm{mm}$ and $1,260 \mathrm{~mm}$, respectively. Further details of the climate conditions, geographic locations, and dominant plant species are listed in Table S1.

Soil sample collection was performed between August and October 2018. There were 54 soil samples (three land use types x six sampling counties x three repetitions). In each $30 \mathrm{~m}$ x $30 \mathrm{~m}$ sampling field, twenty 38 $\mathrm{mm}$-diameter soil cores were collected at $15 \mathrm{~cm}$ soil depth and pooled. Each soil sample was passed through a 2-mm sieve to remove rocks, roots, and organic debris. Physicochemical properties were determined for air-dried soil. Genomic DNA was extracted from soil stored at $-80 \operatorname{deg}$.

\subsection{Soil physicochemical property measurements}

The $\mathrm{pH}$ of $10 \mathrm{~g}$ soil suspended in $25 \mathrm{~mL}$ water was measured with a glass electrode $\mathrm{pH}$ meter. Exchangeable calcium $(\mathrm{Ca})$ and magnesium $(\mathrm{Mg})$ were displaced via compulsive exchange in $1 \mathrm{M}$ ammonium acetate $(\mathrm{pH} 7)$. Soil organic carbon (SOC) was measured by dichromate redox colorimetry. Particulate organic $\mathrm{C}$ (POC) and mineral-associated organic C (MOC) were isolated by size fractionation $(>53 \mu \mathrm{m}$ and $<53 \mu \mathrm{m})$ and analyzed in the same way as the bulk SOC. Total N (TN) was determined using an elemental (CN) analyzer (Vario MAX CN; Elementar, Hanau, Germany). Ammonium N $\left(\mathrm{NH}_{4}{ }^{+}\right)$and nitrate $\mathrm{N}\left(\mathrm{NO}_{3}{ }^{-}\right)$ were extracted from $10 \mathrm{~g}$ fresh soil by extraction with $0.5 \mathrm{M} \mathrm{KCl}$ and measured with an auto flow analyzer. Total phosphorus (TP) and available phosphorus (AP) were determined by digestion in a solution containing $\mathrm{H}_{2} \mathrm{SO}_{4}$ and $\mathrm{HClO}_{4}$ and by molybdenum blue colorimetry, respectively (Hu et al., 2021; Xiao et al., 2019, 2020).

\subsection{Soil DNAextraction and amplicon sequencing}

The total DNA was extracted from $0.5 \mathrm{~g}$ soil samples using a FastDNA Spin Kit (MP Biomedicals, Santa Ana, CA, USA) according to the manufacturer's instructions. DNA quality and quantity were determined with a NanoDrop 2000 UV-vis spectrophotometer (Thermo Fisher Scientific, Wilmington, DE, USA). Bacterial $16 \mathrm{~S}$ rDNA gene was amplified using the primer pairs 338F (5'-ACTCCTACGGGAGGCAGCAG-3') and 806R (5'-GGACTACHVGGGTWTCTAAT$\left.3^{\prime}\right)$. Fungal ITS and protist $18 \mathrm{~S}$ rRNA genes were amplified with the primer sets ITS1F (5'-CTTGGTCATTTAGAGGAAGTAA-3')/ITS2R (5'-GCTGCGTTCTTCATCGATGC$\left.3^{\prime}\right)$ and TAReuk454FWD1 (5'-CCAGCA(G/C)C(C/T)GCGGTAATTCC-3')/TAReukREV3 (5'ACTTTCGTTCTTGAT (C/T)(A/G)A-3'), respectively. Samples were distinguished by attaching barcode sequences to each primer.

PCR was performed in a $20 \mu \mathrm{L}$ mixture containing $4 \mu \mathrm{L}$ of $5 \times$ FastPfu Buffer, $2 \mu \mathrm{L}$ of $2.5 \mathrm{mM}$ dNTPs, 0.8 $\mu \mathrm{L}$ of $5 \mu \mathrm{M}$ forward and reverse primers, $0.4 \mu \mathrm{L}$ TaKaRa rTaq DNA polymerase (TaKaRa Bio Inc., Shiga,

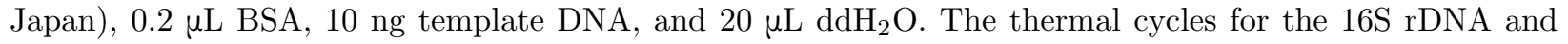
ITS genes were, $95{ }^{\circ} \mathrm{C}$ for $3 \mathrm{~min}, 27$ cycles and 35 cycles for $16 \mathrm{~S} \mathrm{rDNA}$ and ITS genes, respectively, $95{ }^{\circ} \mathrm{C}$ for $30 \mathrm{~s}, 55{ }^{\circ} \mathrm{C}$ for $30 \mathrm{~s}, 72{ }^{\circ} \mathrm{C}$ for $45 \mathrm{~s}$, and a final extension at $72{ }^{\circ} \mathrm{C}$ for $10 \mathrm{~min}$. The PCR program used for protist $18 \mathrm{~S}$ rRNA gene was, initial denaturation at $95{ }^{\circ} \mathrm{C}$ for $5 \mathrm{~min}, 10$ cycles of denaturation at $94{ }^{\circ} \mathrm{C}$ for $30 \mathrm{~s}$, annealing at $57{ }^{\circ} \mathrm{C}$ for $45 \mathrm{~s}$, extension at $72{ }^{\circ} \mathrm{C}$ for $60 \mathrm{~s}, 25$ cycles of denaturation at $94{ }^{\circ} \mathrm{C}$ for $30 \mathrm{~s}$, 
annealing at $45{ }^{\circ} \mathrm{C}, 47{ }^{\circ} \mathrm{C}, 48{ }^{\circ} \mathrm{C}$, and $49{ }^{\circ} \mathrm{C}$ for $45 \mathrm{~s}$ each, extension at $72{ }^{\circ} \mathrm{C}$ for $60 \mathrm{~s}$, and a final extension at $72{ }^{\circ} \mathrm{C}$ for 2 min. PCR was performed at Shanghai Majorbio Bio-Pharm Technology Co. Ltd. (Shanghai, China) on an Illumina MiSeq PE300 platform (Illumina, San Diego, CA, USA).

\subsection{Sequence analysis}

Bioinformatic analyses of all three amplicons were performed with QIIME 2 2021.2 (Bolyen et al., 2019). The raw reads were imported into the QIIME 2 environment and denoised with the DADA2 algorithm via the q2-data2 plugin (Callahan et al., 2016). Operational taxonomic units (OTUs) were selected at 97\% sequence similarity in the q2-vsearch plugin (Rognes et al., 2016). OTU taxonomies for bacteria, fungi, and protist were assigned using the q2-feature-classifier (Bokulich et al., 2018) vs. the SILVA_v132 (Quast et al., 2012), UNITE_v8.3 (Nilsson et al., 2019), and PR2 (V4.13.0) (Guillou et al., 2012) reference sequences, respectively. Alpha-diversity metrics (richness and Shannon index) were calculated in the "RAM" package of R (R Core Team, Vienna, Austria).

\subsection{Statistical analysis}

Data were processed in R v. 3.6.3 (R Core Team). Significant differences in microbial diversity, microbial groups, and environmental factors among vegetation types were analyzed by one-way ANOVA and Duncan's post hoc test $(p<0.05)$. Three-way nested PERMANOVA was used to determine the main and interactive effects of MAT, MAP, and vegetation type on microbial diversity and community composition (Xiao et al., 2019). Non-metric multidimensional scaling (NMDS) was performed to reveal dissimilarities in microbial, fungal, and protist community composition among treatments. Pearson's correlation coefficients and the Mantel test were applied to determine the relationships among environmental factors (geographical factors, climatic conditions, and soil properties), microbial diversity, and community composition.

To determine the structure and identify interactions among microbial groups, bacterial, fungal, and protist community networks were constructed across all samples and vegetation types under low (GZ) and high (GX) climate conditions. Spearman correlations were calculated to clarify the associations among the microbial taxa detected in $>1 / 3$ of all samples per network. Significant Spearman associations $(\rho>0.75 ; 1,000-$ fold permutations; $p<0.05$ ) and the corresponding OTUs served as network nodes and edges, respectively. Positive and negative associations suggested cooperative and competitive relationships, respectively. Network properties such as node, edge, density, and degree were calculated in each network using the "igraph" package in R (R Core Team) (Csardi and Nepusz, 2006).

Structural equation modeling (SEM) based on SPSS Amos 21 (IBM Corp., Armonk, NY, USA) was conducted to evaluate the causal relationships among MAT, vegetation type, soil property, and microbial community composition (Hu et al., 2021; Yang et al., 2017). To simplify the SEM, a principal component analysis (PCA) of the first component (PC1) was applied to represent soil properties and microbial community compositions based on bacterial, fungal, and protist NMDS axes 1 and 2. Soil properties included $\mathrm{pH}$, soil exchangeable $\mathrm{Ca}^{2+}(\mathrm{Ca})$, soil exchangeable $\mathrm{Mg}^{2+}(\mathrm{Mg})$, soil organic carbon (SOC), particulate organic carbon (POC), mineral-associated organic carbon (MOC), total nitrogen (TN), ratio of soil carbon to soil nitrogen $(\mathrm{C} / \mathrm{N})$, ammonium nitrogen $\left(\mathrm{NH}_{4}{ }^{+}\right)$, nitrate nitrogen $\left(\mathrm{NO}_{3}{ }^{-}\right)$, total phosphorus $(\mathrm{TP})$, and available phosphorus (AP).

\section{RESULTS}

\subsection{Bacterial, fungal, and protist diversity and community composition}

Only bacterial diversity was affected by temperature (Table 1). Bacterial richness and the Shannon indices for plantation forest and shrubland were lower in Guangxi (high temperature) than Guizhou (low temperature) (Fig. 2a). Vegetation type significantly affected bacterial, fungal, and protist diversity (Table 1). Bacterial richness and Shannon index were lower under shrubland than cropland (except for richness in Guizhou) (Fig. 2a). Fungal richness was higher in shrubland than cropland under both climate conditions (Fig. 2b). At Guangxi, protist Shannon index was lower under plantation forest and shrubland than cropland. Cropland 
protist richness was higher than that of shrubland at Guangxi (Fig. 2c). There were no differences between plantation forest and shrubland in terms of bacterial, fungal, and or protistan diversity (Fig. 2).

Across all sites, phylum-level bacterial community composition was dominated by Actinobacteria (29.3\%), Proteobacteria (25.6\%), and Acidobacteria (16.7\%) (Fig. 3a). The most abundant fungal phyla were Ascomycota $(45.0 \%)$ and Basidiomycota $(27.9 \%)$ (Fig. 3b). The main protist phyla were Cercozoa (33.9\%) and Apicomplexa (22.1\%) (Fig. 3c). NMDS ordination revealed that bacterial, fungal, and protist community composition differed among vegetation types between Guizhou and Guangxi. Bacterial, fungal, and protist community composition differed between cropland and vegetation recovery but were similar between plantation forest and shrubland (Figs. 3d-f). Temperature and vegetation type significantly affected bacterial, fungal, and protist community composition (Table 1).

The relative abundance of Proteobacteria (bacteria) under all vegetation types was lower at Guangxi than Guizhou (Table S2, Fig. S2). The relative abundance of Mucoromycota (fungi) was higher under plantation forest and shrubland at Guizhou than it was at Guangxi (Table S3, Fig. S3). The relative abundance of Cercozoa (protist) was higher under plantation forest and shrubland at Guizhou than it was at Guangxi (Table S4, Fig. S4). Relative bacterial phyla Cyanobacteria, Gemmatimonadetes, and Nitrospirae abundances were higher under cropland than plantation forest or shrubland. Relative Proteobacteria and Verrucomicrobia abundances were higher under shrubland than cropland (Table S2, Fig. S2). Relative fungal phyla Ascomycota and Mucoromycota abundances were higher under cropland than plantation forest and shrubland. Nevertheless, the opposite was true for Basidiomycota (Table S3, Fig. S3). Relative protist phyla Ciliophora, Lobosa, and Ochrophyta abundances were higher under cropland than plantation forest or shrubland. However, the opposite was true for Apicomplexa (Table S4, Fig. S4).

\subsection{Co-occurrence networks amongbacterial, fungal, and protist taxa}

Microbiome network complexity was greater at Guizhou (GZ) than Guangxi (GX). There were more nodes and edges under GZ than GX. The most densely connected network occurred under cropland (Table 2, Fig. 4). There were fewer positive and negative correlation links among bacterial, fungal, and protist taxa under vegetation restoration than cropland. Shrubland had the fewest positive and negative correlation links among microbial taxa (Fig. 4). Node connectivity was greater under cropland than plantation forest or shrubland. Shrubland had the fewest node connections. Under all vegetation and both climate types, bacteria had the most nodes, followed by fungi and protists (Table 2, Fig. S5).

Acidobacteria (bacteria), Ascomycota (fungi), and Cercozoa (protist) formed remarkably centralized networks and showed the most links with other microbial groups (Table S5, Fig. 4). Bacterial phyla Acidobacteria and Proteobacteria were the most closely connected with Ascomycota and Cercozoa. The strongest and most numerous links between fungal and protist taxa were determined for Ascomycota and Cercozoa, followed by Ascomycota and Lobosa (Table S5). There were more interactions between bacterial and fungal taxa (edge links) than there were between bacterial and protist taxa or between fungal and protist taxa. The proportions of edges linking bacteria to protists were lower under plantation forest and shrubland than cropland. Conversely, the proportions of edges linking fungi to protists were higher under plantation forest and shrubland than cropland (Table 2).

\subsection{Relationships among environmental factors and bacterial, fungal, and protist communities}

The various bacterial, fungal, and protist taxa had different effects on soil carbon (SOC, POC, and MOC), nitrogen (TN, $\mathrm{NH}_{4}{ }^{+}$, and $\mathrm{NO}_{3}{ }^{-}$), and phosphorus (TP and $\mathrm{AP}$ ). More bacterial, fungal, and protist OTUs correlated with $\mathrm{C}$ and $\mathrm{N}$ than they did with $\mathrm{P}$ (Fig. 5). For bacterial taxa, soil SOC, POC, and MOC were most strongly correlated with Proteobacteria. Acidobacteria and Proteobacteria had the most OTUs correlated with soil TN, $\mathrm{NH}_{4}{ }^{+}, \mathrm{NO}_{3}{ }^{-}$, TP, and AP (Fig. 5a). Soil carbon (SOC, POC, and MOC), nitrogen ( TN, $\mathrm{NH}_{4}{ }^{+}$, and $\mathrm{NO}_{3}{ }^{-}$), and phosphorus (TP and $\mathrm{AP}$ ) were strongly correlated with fungal phyla Ascomycota (Fig. 5b). Protist phyla Cercozoa were strongly correlated with soil C, N, and P (Fig. 5c).

Pearson's correlation coefficients showed that bacterial richness and Shannon index were negatively correlated 
with MAT, MAP, and MOC but positively correlated with latitude and altitude (Fig. 6a). Fungal diversity was not significantly correlated with any geographical factor, climate condition, or soil property (Fig. 6b). Protist diversity was positively correlated with AP but negatively correlated with SOC, POC, TN, and $\mathrm{NH}_{4}{ }^{+}$ (Fig. 6c). Bacterial, fungal, and protist community compositions were strongly affected by environmental factors (geography, climate, and soil physicochemistry) (Fig. 6).

Structural equation modeling (SEM) evaluated the linkages among environmental factors and microbial community composition, and ranked the relative importance of each driver on the microbial communities. Temperature and vegetation type directly influenced soil property and indirectly affected bacterial, fungal, and protist community composition. MAT had greater standard total effect on bacterial and fungal community composition than it did on protist community composition. Vegetation type had the highest standard total effect on protist community composition followed by fungal community composition and bacterial community composition. Bacterial and fungal community composition was affected by MAT and vegetation type. Moreover, vegetation type and soil property had greater influences than MAT on protist community composition (Fig. 7).

\section{DISCUSSION}

\subsection{Bacterial, fungal, and protist communities differ among climate and vegetation types}

Bacterial diversity was significantly affected by MAT and vegetation type, whereas fungal and protist diversity were influenced by the vegetation type alone. Elevated temperatures in humid regions enhance SOM decomposition by accelerating microbial activity and turnover (Allison et al., 2010; Zhao et al., 2019a). The high soil exchangeable Ca content of karst soil inhibits SOM decomposition by forming stable aggregates (Briedis et al., 2012; Wiesmeier et al., 2019). Our previous study found that high exchangeable Ca during vegetation restoration improves SOC accumulation and negates the effect of temperature increases on SOC decomposition (Hu et al., 2021). The fact that MOC was higher under the plantation forest and shrubland of Guangxi than it was under those of Guizhou suggests that readily decomposable organic $\mathrm{C}$ was more rapidly degraded than recalcitrant $\mathrm{C}$ at high temperatures (Fig. S1; Samal et al., 2020). Hence, labile organic C decreased with increasing temperature. Bacterial groups could be stimulated under the condition of high labile organic C (Poll et al., 2008). Consequently, there was higher bacterial diversity under the plantation forest and shrubland of Guizhou than there was under those of Guangxi. In contrast to bacteria, mycorrhizal and other fungi are highly dependent on their mutualistic relationships with plants (Newsham et al., 2009; Schmidt et al., 2014). Fungi utilize the polymerized litter fraction such as lignin and cellulose (Fontaine et al., 2011). High plant residue input under plantation forest and shrubland increases fungal diversity by supplying abundant organic substrates (Chen et al., 2017; Waldrop et al., 2006). This phenomenon explains our observation that fungal richness was greater under plantation forest and shrubland than it was under cropland except for plantation forest at Guizhou. Conversely, the bacterial Shannon index was higher under cropland than shrubland. Bacteria have a growth advantage over fungi in highly fertile agricultural soils (Cai et al., 2018). Enhanced bacterial diversity under cropland promotes protist consumers and results in higher protist diversity under cropland than vegetation restoration after cropland abandonment (Guo et al., 2018). Overall, these results suggest that high fungal diversity under vegetation restoration may contribute to SOC accumulation by stimulating plant residue decomposition.

Temperature and vegetation type influenced bacterial, fungal, and protist community composition. Bacterial phylum Proteobacteria prefer labile organic carbon and their abundance is positively correlated with $\mathrm{C} / \mathrm{N}$ (Fierer et al., 2007; Hermans et al., 2017). Here, C/N was higher at Guizhou than Guangxi (Fig. S1). Therefore, Proteobacteria had higher relative abundance at the former than the latter location. Compared with cropland, shrubland provided greater available organic $\mathrm{C}$ by increasing plant residue inputs. For this reason, Proteobacteria were more abundant under shrubland than cropland. Basidiomycota include symbiotic fungi while Ascomycota include free-living saprotrophs (Baldrian et al., 2011; Read and PerezMoreno, 2003). Basidiomycota promote plant litter decomposition (Baldrian et al., 2011; Toljander et al., 2006). Consequently, there was greater Basidiomycota abundance under plantation forest and shrubland than cropland. Moreover, Ascomycota abundance was greater under high-AP conditions (Dang et al., 2017). 
Thus, relative Ascomycota abundance was higher under cropland than plantation forest or shrubland because cropland had comparatively higher AP content (Figs. S1 and S3). In general, anthropogenic disturbance and environmental pressure are greater in cropland than plantation forest or shrubland (Santos et al., 2020). Protist community composition under cropland was markedly different from that vegetation restoration (Grossmann et al., 2016; Santos et al., 2020; Schulz et al., 2019). For this reason, Ciliophora, Lobosa, and Ochrophyta were more abundant under cropland than they were under plantation forest or shrubland. Certain Apicomplexa are plant parasites and were more abundant under plantation forest and shrubland than they were under cropland (Seppey et al., 2020). Taken together, the foregoing observations indicate that bacterial, fungal, and protist community composition markedly differ between cropland and vegetation restoration.

Contrary to our hypothesis, bacterial, fungal, and protist diversity and community composition under plantation forest and shrubland were similar in the subtropical karst region. The southwestern karst region is geologically fragile, and intense anthropogenic disturbance there has led to rapid nutrient loss (Wang et al., 2019; Wen et al., 2016; Xu et al., 2021; Zhang et al., 2013). In general, soil nutrient levels were limited in the early stages of plantation forest and shrubland restoration in the southwestern karst region (Hu et al., 2021). Soil available nutrient levels are key factors regulating microbial diversity and community composition. As bioavailable nutrient content was similar between plantation forest and shrubland, they did not differ in terms of microbial diversity or community composition as vegetation restoration progressed. Nevertheless, plant diversity was greater in shrubland than it was in single-species plantation forest (Hu et al., 2020). These results suggest that in the karst region with plantation forest and shrubland restoration, nutrient availability plays a more important role than the plant community in determining bacterial, fungal, and protist communities.

\subsection{Elevated temperature and precipitation weaken microbial interactions within the co- occurrence networks}

The soil microbiome network plays a key role in helping us understand potential biotic interactions there (Feng et al., 2021; Sanaei et al., 2021; Zhao et al., 2019b). Interspecific interactions among bacterial, fungal, and protist groups were stronger at Guizhou than Guangxi. This finding was contrary to our hypothesis. There were more bacterial nodes (OTUs) than fungal or protist nodes. Hence, there were large, ubiquitous bacterial populations. Readily decomposable organic $\mathrm{C}$ should augment bacterial diversity to a greater extent at Guizhou than Guangxi (Poll et al., 2008; Samal et al., 2020). High bacterial diversity fosters linkages with fungi and protists. There were more bacterial nodes at Guizhou than Guangxi. By contrast, fungi and protists had similar numbers of nodes at both locations. These results suggest stronger network interactions at Guizhou than Guangxi primarily because bacterial diversity was greater than fungal or protist diversity at both locations. Similarly, elevated bacterial diversity under cropland resulted in a greater number of network interactions than those under plantation forest or shrubland. Fungi are more tolerant of high soil C/N than bacteria (De Deyn et al., 2008; Wang et al., 2015). Fungi might grow better in plantation forest and shrubland soil than in cropland soil as the latter has comparatively lower C/N (Fig. S1m). Fungi are vital plant biomass decomposers and degrade plant litter containing lignin and cellulose (Fontaine et al., 2011; Zeilinger et al., 2016). At this case, correlations among fungal and protist taxa were stronger under plantation forest and shrubland than cropland. Thus, the fungal community plays a crucial role in vegetation restoration.

Co-occurrence patterns can also identify keystone and indicator taxa (Fournier et al., 2020; Wang et al., 2021). Bacterial phyla Acidobacteria and Proteobacteria, fungal phyla Ascomycota and Basidiomycota, and protist phyla Cercozoa and Lobosa formed the most links with other microbial groups and are, therefore, potentially vital to soil food webs. Protists prey on bacteria and fungi, thereby modifying microbial communities (Geisen et al., 2018). Cercozoa and Lobosa are phagotrophs that consume Acidobacteria, Proteobacteria, and Ascomycota (de Araujo et al., 2018; Seppey et al., 2020). These predator-prey relationships were stronger at Guizhou than Guangxi. Hence, predation of microbial decomposers by protists is more important at low than high temperature (Geisen et al., 2021). Soil moisture content was usually higher at Guizhou than Guangxi 
because low temperature partially retards evaporation. Protist movement, feeding, and multiplication are all affected by the water films in the soil pore spaces (Ritz, 2011; Stefan et al., 2014). Consequently, predation of bacteria and fungi by protists was strong in Guizhou soil.

\subsection{Predominant factors governing bacterial, fungal, and protist communities}

Soil C, N, and P were strongly linked to Proteobacteria, Acidobacteria, Ascomycota, and Cercozoa (Fig. 5). Nutrient cycling-related Proteobacteria and Acidobacteria are copiotrophic and oligotrophic, respectively, and are sensitive to changes in nutrient levels (Ai et al., 2015; Fierer et al., 2007). Increasing soil $\mathrm{C}$ and $\mathrm{N}$ availability stimulates Proteobacteria growth whereas Acidobacteria prefer to live under nutrient-poor conditions (Ai et al., 2015; Dai et al., 2018; Fierer et al., 2012). Ascomycota are free-living saprotrophic fungi that are involved in organic matter decomposition and regulate resource availability (Baldrian et al., 2011; Chen et al., 2021). Here, Proteobacteria, Acidobacteria, Ascomycota, and Cercozoa were the dominant taxa and played important roles in modulating the soil $\mathrm{C}, \mathrm{N}$, and $\mathrm{P}$ nutrient content.

In this study, temperature, vegetation type, and soil properties markedly influenced the composition of bacterial, fungal, and protist communities. Temperature was the key climate factor affecting bacterial and fungal community composition. Bacterial and fungal activity increased with soil temperature in the range of 5-30 드 (BÁRcenas-Moreno et al., 2009; Pettersson and Bååth, 2003; Pietikainen et al., 2005). The increased in soil temperature improved the growth of certain bacterial and fungal taxa, thereby altering bacterial and fungal community composition. Fungi, such as mycorrhizal fungi form beneficial mutualistic association with the roots of their plant host (Johnson et al., 2004; Smith and Read, 2010). Compared with bacterial community composition, fungal community composition was more strongly affected by vegetation type. However, protist community composition was more sensitive to vegetation type and soil physicochemistry than it was to soil temperature. These discoveries confirm those of previous studies reporting that differences in precipitation rate and water availability rather than changes in soil temperature were limiting factors influencing protist abundance (Stefan et al., 2014). Taken together, temperature and vegetation were the primary factors for predicting the changes in bacterial and fungal community composition, while vegetation and soil property are the main determinants of protist taxa.

\section{CONCLUSIONS}

The present study revealed that soil bacteria, fungi, protists, and the food webs they form respond differently to vegetation type depending on the ambient temperature. We demonstrated that bacterial, fungal, and protist diversity and community composition differed under vegetation restoration and cropland. However, bacterial, fungal, and protist diversity and community composition were similar under plantation forest and shrubland because the soils under these vegetation types had similar nutrient profiles. There were significant differences in bacterial, fungal, and protist community composition between Guizhou (MAT, $14.6{ }^{\circ} \mathrm{C}$ ) and Guangxi (MAT, $20.9{ }^{\circ} \mathrm{C}$ ) because of the substantial temperature difference between these regions. The low temperature at Guizhou strengthened interspecific interactions among bacterial, fungal, and protist taxa. There might have been relatively greater bacterial diversity at Guizhou than at Guangxi. Similarly, high bacterial diversity in cropland soil caused to stronger interactions in the microbiome network under cropland than under plantation forest or shrubland. Hence, it is primarily bacteria that shape the cooccurrence networks among microbial taxa. The protist phyla Cercozoa and Lobosa prey upon the bacterial phyla Acidobacteria and Proteobacteria, and the fungal phylum Ascomycota. Proteobacteria, Acidobacteria, Ascomycota, and Cercozoa predominated in the karst and regulated the variations in the $\mathrm{C}, \mathrm{N}$, and $\mathrm{P}$ nutrient levels in the soils there. Bacterial and fungal community compositions were strongly affected by changing temperature and vegetation type whereas protist community composition was influenced mainly by vegetation type and soil properties. Taken together, these findings underscore the importance of evaluating the relationships among bacterial, fungal, and protist taxa during vegetation restoration. They also suggest that temperature must be considered in during soil nutrient cycling as microbial interactions are strongly influenced by it. Fungi were comparatively more dependent than bacteria on plant community. Nevertheless, in the present study, we did not compare plant diversity between plantation forest and shrubland. Future studies should integrate plant characteristics and examine the complex relationships among microorganisms 
and vegetation.

\section{ACKNOWLEDGEMENTS}

The study was supported by the National Natural Science Foundation of China (U20A2011; 41930652; 32001215; 31870502; 31870503); CAS Key Laboratory of Agro-ecological Processes in Subtropical Region, Institute of Subtropical Agriculture (ISA2020104); the China Postdoctoral Science Foundation (2020M682586); and Guangxi Natural Science Foundation Program (2020JJB130003; 2020GXNSFDA238012).

\section{REFERENCES}

Ai, C., Liang, G., Sun, J., Wang, X., He, P., Zhou, W., \& He, X. (2015). Reduced dependence of rhizosphere microbiome on plant-derived carbon in 32-year long-term inorganic and organic fertilized soils. Soil Biology and Biochemistry, 80, 70-78.

Allison, S. D., Wallenstein, M. D., \& Bradford, M. A. (2010). Soil-carbon response to warming dependent on microbial physiology. Nature Geoscience, 3 (5), 336-340.

Baldrian, P., Kolařík, M., Štursová, M., Kopecký, J., Valášková, V., Větrovský, T., .. \& Voříšková, J. (2012). Active and total microbial communities in forest soil are largely different and highly stratified during decomposition. The ISME Journal , 6 (2), 248-258.

Baldrian, P., Vořiššová, J., Dobiášová, P., Merhautová, V., Lisá, L., \& Valášková, V. (2011). Production of extracellular enzymes and degradation of biopolymers by saprotrophic microfungi from the upper layers of forest soil. Plant and Soil , 338 (1), 111-125.

BÁRcenas-Moreno, G., GÓMez-BrandÓN, M., Rousk, J., \& BÅÅTh, E. (2009). Adaptation of soil microbial communities to temperature: comparison of fungi and bacteria in a laboratory experiment. Global Change Biology , 15 (12), 2950-2957.

Bokulich, N.A., Kaehler, B.D., Rideout, J.R., Dillon, M., Bolyen, E., Knight, R., Huttley, G.A., \& Caporaso, J.G. (2018). Optimizing taxonomic classification of marker-gene amplicon sequences with QIIME 2's q2feature-classifier plugin. Microbiome , 6 (1), 1-17.

Bolyen, E., Rideout, J. R., Dillon, M. R., Bokulich, N. A., Abnet, C. C., Al-Ghalith, G. A., . . \& Caporaso, J. G. (2019). Reproducible, interactive, scalable and extensible microbiome data science using QIIME 2. Nature Biotechnology , 37 (8), 852-857.

Briedis, C., de Moraes Sá, J. C., Caires, E. F., de Fátima Navarro, J., Inagaki, T. M., Boer, A., ... \& Dos Santos, J. B. (2012). Soil organic matter pools and carbon-protection mechanisms in aggregate classes influenced by surface liming in a no-till system. Geoderma , 170 , 80-88.

Cai, Z. Q., Zhang, Y. H., Yang, C., \& Wang, S. (2018). Land-use type strongly shapes community composition, but not always diversity of soil microbes in tropical China. Catena , 165 , 369-380.

Callahan, B. J., McMurdie, P. J., Rosen, M. J., Han, A. W., Johnson, A. J. A., \& Holmes, S. P. (2016). DADA2: high-resolution sample inference from Illumina amplicon data. Nature Methods , 13 (7), 581-583.

Chen, H., Zhang, W., Wang, K., \& Hou, Y. (2012). Soil organic carbon and total nitrogen as affected by land use types in karst and non-karst areas of northwest Guangxi, China. Journal of the Science of Food and Agriculture, 92 (5), 1086-1093.

Chen, L., Xiang, W., Ouyang, S., Wu, H., Xia, Q., Ma, J., .. \& Kuzyakov, Y. (2021). Tight coupling of fungal community composition with soil quality in a Chinese fir plantation chronosequence. Land Degradation E Development , 32 (3), 1164-1178.

Chen, Y. L., Xu, T. L., Veresoglou, S. D., Hu, H. W., Hao, Z. P., Hu, Y. J., .. \& Chen, B. D. (2017). Plant diversity represents the prevalent determinant of soil fungal community structure across temperate grasslands in northern China. Soil Biology and Biochemistry , 110 , 12-21. 
Crowther, T. W., Van den Hoogen, J., Wan, J., Mayes, M. A., Keiser, A. D., Mo, L., .. \& \& Maynard, D. S. (2019). The global soil community and its influence on biogeochemistry. Science, 365 (6455).

Csardi, G., \& Nepusz, T. (2006). The igraph software package for complex network research. InterJournal, Complex Systems , 1695 (5), 1-9.

Dai, Z., Su, W., Chen, H., Barberan, A., Zhao, H., Yu, M., .. \& \& Xu, J. (2018). Long-term nitrogen fertilization decreases bacterial diversity and favors the growth of Actinobacteria and Proteobacteria in agro-ecosystems across the globe. Global Change Biology , 24 (8), 3452-3461.

Dang, P., Yu, X., Le, H., Liu, J., Shen, Z., \& Zhao, Z. (2017). Effects of stand age and soil properties on soil bacterial and fungal community composition in Chinese pine plantations on the Loess Plateau. PLoS One , 12 (10), e0186501.

de Araujo, A.S.F., Mendes, L.W., Lemos, L.N., Antunes, J.E.L., Beserra, J.E.A., Figueiredo, M.d.V.B., de Almeida Lopes, A.C., Gomes, R.L.F., Bezerra, W.M., Melo, V.M.M., de Araujo, F.F., \& Geisen, S. (2018). Protist species richness and soil microbiome complexity increase towards climax vegetation in the Brazilian Cerrado. Communications Biology , 1 (1), 1-8.

De Deyn, G. B., Cornelissen, J. H., \& Bardgett, R. D. (2008). Plant functional traits and soil carbon sequestration in contrasting biomes. Ecology Letters , 11 (5), 516-531.

Fan, D., Kong, W., Wang, F., Yue, L., \& Li, X. (2020). Fencing decreases microbial diversity but increases abundance in grassland soils on the Tibetan Plateau. Land Degradation 83 Development, 31 (17), 2577-2590.

Feng, W., Zhang, Y., Lai, Z., Qin, S., Yan, R., Sun, Y., \& She, W. (2021). Soil bacterial and eukaryotic co-occurrence networks across a desert climate gradient in northern China. Land Degradation 8 S Development , 32 (5), 1938-1950.

Fierer, N., Bradford, M. A., \& Jackson, R. B. (2007). Toward an ecological classification of soil bacteria. Ecology , 88 (6), 1354-1364.

Fierer, N., Lauber, C. L., Ramirez, K. S., Zaneveld, J., Bradford, M. A., \& Knight, R. (2012). Comparative metagenomic, phylogenetic and physiological analyses of soil microbial communities across nitrogen gradients. The ISME Journal , 6 (5), 1007-1017.

Fontaine, S., Henault, C., Aamor, A., Bdioui, N., Bloor, J., Maire, V., Mary, B., Revaillot, S., \& Maron, P.A. (2011). Fungi mediate long term sequestration of carbon and nitrogen in soil through their priming effect. Soil biology and Biochemistry , 43 (1), 86-96.

Fournier, B., Dos Santos, S.P., Gustavsen, J.A., Imfeld, G., Lamy, F., Mitchell, E.A., Mota, M., Noll, D., Planchamp, C., \& Heger, T.J. (2020). Impact of a synthetic fungicide (fosetyl-Al and propamocarbhydrochloride) and a biopesticide (Clonostachys rosea ) on soil bacterial, fungal, and protist communities.Science of The Total Environment, 738 , 139635.

Geisen, S., Hu, S., dela Cruz, T. E. E., \& Veen, G. C. (2021). Protists as catalyzers of microbial litter breakdown and carbon cycling at different temperature regimes. The ISME Journal , 15 (2), 618-621.

Geisen, S., Mitchell, E. A., Adl, S., Bonkowski, M., Dunthorn, M., Ekelund, F., .. \& \& Lara, E. (2018). Soil protists: a fertile frontier in soil biology research. FEMS Microbiology Reviews , 42 (3), 293-323.

Grossmann, L., Jensen, M., Heider, D., Jost, S., Glucksman, E., Hartikainen, H., Mahamdallie, S.S., Gardner, M., Hoffmann, D., Bass, D., \& Boenigk, J. (2016). Protistan community analysis: key findings of a large-scale molecular sampling. The ISME Journal , 10 (9), 2269-2279.

Guillou, L., Bachar, D., Audic, S., Bass, D., Berney, C., Bittner, L., .. \& \& Christen, R. (2012). The Protist Ribosomal Reference database (PR2): a catalog of unicellular eukaryote small sub-unit rRNA sequences with curated taxonomy. Nucleic Acids Research , 41 (D1), D597-D604. 
Guo, S., Xiong, W., Xu, H., Hang, X., Liu, H., Xun, W., Li, R., \& Shen, Q. (2018). Continuous application of different fertilizers induces distinct bulk and rhizosphere soil protist communities. European Journal of Soil Biology , 88, 8-14.

Hermans, S.M., Buckley, H.L., Case, B.S., Curran-Cournane, F., Taylor, M., \& Lear, G. (2017). Bacteria as emerging indicators of soil condition. Applied and Environmental Microbiology , 83 (1), e02826-16.

Hu, P. L., Liu, S. J., Ye, Y. Y., Zhang, W., Wang, K. L., \& Su, Y. R. (2018). Effects of environmental factors on soil organic carbon under natural or managed vegetation restoration. Land Degradation 85 Development , 29 (3), 387-397.

Hu, P., Xiao, J., Zhang, W., Xiao, L., Yang, R., Xiao, D., Zhao, J., \& Wang, K. (2020). Response of soil microbial communities to natural and managed vegetation restoration in a subtropical karst region. Catena , 195,104849 .

Hu, P., Zhang, W., Chen, H., Li, D., Zhao, Y., Zhao, J., Xiao, J., Wu, F., He, X., Luo, Y., \& Wang, K. (2021). Soil carbon accumulation with increasing temperature under both managed and natural vegetation restoration in calcareous soils.Science of The Total Environment, 767, 145298.

Jiang, Z., Lian, Y., \& Qin, X. (2014). Rocky desertification in Southwest China: impacts, causes, and restoration. Earth-Science Reviews, 132 , 1-12.

Johnson, D., Vandenkoornhuyse, P.J., Leake, J.R., Gilbert, L., Booth, R.E., Grime, J.P., Young, J.P.W., \& Read, D.J. (2004). Plant communities affect arbuscular mycorrhizal fungal diversity and community composition in grassland microcosms. New Phytologist, 161 (2), 503-515.

Kara, E. L., Hanson, P. C., Hu, Y. H., Winslow, L., \& McMahon, K. D. (2013). A decade of seasonal dynamics and co-occurrences within freshwater bacterioplankton communities from eutrophic Lake Mendota, WI, USA. The ISME Journal , 7 (3), 680-684.

Ladygina, N., \& Hedlund, K. (2010). Plant species influence microbial diversity and carbon allocation in the rhizosphere. Soil Biology and Biochemistry , 42 (2), 162-168.

Lan, J. (2021). Responses of soil organic carbon components and their sensitivity to karst rocky desertification control measures in Southwest China. Journal of Soils and Sediments , 21 (2), 978-989.

Li, D., Wen, L., Xiao, K., Song, T., \& Wang, K. (2021). Responses of soil gross nitrogen transformations to three vegetation restoration strategies in a subtropical karst region. Land Degradation 83 Development, 32 (8), 2520-2527.

Li, S. L., Liu, C. Q., Chen, J. A., \& Wang, S. J. (2021). Karst ecosystem and environment: Characteristics, evolution processes, and sustainable development. Agriculture, Ecosystems \&6 Environment , 306 , 107173.

Lian, T., Jin, J., Wang, G., Tang, C., Yu, Z., Li, Y., Liu, J., Zhang, S., \& Liu, X. (2017). The fate of soybean residue-carbon links to changes of bacterial community composition in Mollisols differing in soil organic carbon. Soil Biology and Biochemistry, 109 , 50-58.

Liu, G. Y., Chen, L. L., Shi, X. R., Yuan, Z. Y., Yuan, L. Y., Lock, T. R., \& Kallenbach, R. L. (2019a). Changes in rhizosphere bacterial and fungal community composition with vegetation restoration in planted forests. Land Degradation 85 Development , 30 (10), 1147-1157.

Liu, X., Zhang, W., Wu, M., Ye, Y., Wang, K., \& Li, D. (2019b). Changes in soil nitrogen stocks following vegetation restoration in a typical karst catchment. Land Degradation 83 Development, 30 (1), 60-72.

Liu, Z., Liu, G., Fu, B., \& Zheng, X. (2008). Relationship between plant species diversity and soil microbial functional diversity along a longitudinal gradient in temperate grasslands of Hulunbeir, Inner Mongolia, China. Ecological Research, 23 (3), 511-518. 
Mellado-Vazquez, P.G., Lange, M., Bachmann, D., Gockele, A., Karlowsky, S., Milcu, A., Piel, C., Roscher, C., Roy, J., \& Gleixner, G. (2016). Plant diversity generates enhanced soil microbial access to recently photosynthesized carbon in the rhizosphere. Soil Biology and Biochemistry , 94, 122-132.

Newsham, K. K., Upson, R., \& Read, D. J. (2009). Mycorrhizas and dark septate root endophytes in polar regions. Fungal Ecology, 2 (1), 10-20.

Nilsson, R.H., Larsson, K.H., Taylor, A.F.S., Bengtsson-Palme, J., Jeppesen, T.S., Schigel, D., Kennedy, P., Picard, K., Glockner, F.O., Tedersoo, L., Saar, I., Koljalg, U., \& Abarenkov, K. (2019). The UNITE database for molecular identification of fungi: handling dark taxa and parallel taxonomic classifications. Nucleic acids research , 47 (D1), D259-D264.

Pettersson, M., \& Baath, E. (2003). Temperature-dependent changes in the soil bacterial community in limed and unlimed soil. FEMS Microbiology ecology , 45 (1), 13-21.

Pietikainen, J., Pettersson, M., \& Baath, E. (2005). Comparison of temperature effects on soil respiration and bacterial and fungal growth rates. FEMS Microbiology Ecology , 52 (1), 49-58.

Poll, C., Marhan, S., Ingwersen, J., \& Kandeler, E. (2008). Dynamics of litter carbon turnover and microbial abundance in a rye detritusphere. Soil Biology and Biochemistry , 40 (6), 1306-1321.

Quast, C., Pruesse, E., Yilmaz, P., Gerken, J., Schweer, T., Yarza, P., Peplies, J., \& Glockner, F.O. (2012). The SILVA ribosomal RNA gene database project: improved data processing and web-based tools. Nucleic Acids Research , 41 (D1), D590-D596.

Read, D. J., \& Perez-Moreno, J. (2003). Mycorrhizas and nutrient cycling in ecosystems-a journey towards relevance? New Phytologist, 157 (3), 475-492.

Ritz, K. (2011). The architecture and biology of soils: Life in inner space. Cabi.

Rognes, T., Flouri, T., Nichols, B., Quince, C., \& Mahe, F. (2016). VSEARCH: a versatile open source tool for metagenomics. PeerJ , 4 , e2584.

Samal, S., Dwivedi, S., Rao, K., Choubey, A.K., Prakash, V., Kumar, S., Mishra, J., Bhatt, B., \& Moharana, P. (2020). Five years' exposure of elevated atmospheric $\mathrm{CO}_{2}$ and temperature enriched recalcitrant carbon in soil of subtropical humid climate. Soil and Tillage Research , 203, 104707.

Sanaei, A., Sayer, E. J., Saiz, H., Yuan, Z., \& Ali, A. (2021). Species co-occurrence shapes spatial variability in plant diversity-biomass relationships in natural rangelands under different grazing intensities. Land Degradation $\&$ Development .

Santos, S.S., Scholer, A., Nielsen, T.K., Hansen, L.H., Schloter, M., \& Winding, A. (2020). Land use as a driver for protist community structure in soils under agricultural use across Europe. Science of The Total Environment, $717,137228$.

Schmidt, S., Nemergut, D., Darcy, J., \& Lynch, R. (2014). Do bacterial and fungal communities assemble differently during primary succession? Wiley Online Library.

Schneider, T., Keiblinger, K.M., Schmid, E., Sterflinger-Gleixner, K., Ellersdorfer, G., Roschitzki, B., Richter, A., Eberl, L., Zechmeister-Boltenstern, S., \& Riedel, K. (2012). Who is who in litter decomposition? Metaproteomics reveals major microbial players and their biogeochemical functions. The ISME Journal , 6 (9), 1749-1762.

Schulz, G., Schneider, D., Brinkmann, N., Edy, N., Daniel, R., Polle, A., Scheu, S., \& Krashevska, V. (2019). Changes in trophic groups of protists with conversion of rainforest into rubber and oil palm plantations. Frontiers in Microbiology, 10, 240.

Seppey, C.V., Broennimann, O., Buri, A., Yashiro, E., Pinto-Figueroa, E., Singer, D., Blandenier, Q., Mitchell, E.A., Niculita-Hirzel, H., Guisan, A., \& Lara, E. (2020). Soil protist diversity in the Swiss western 
Alps is better predicted by topo-climatic than by edaphic variables. Journal of Biogeography , 47 (4), 866-878. Smith, S.E., \& Read, D.J. (2010). Mycorrhizal symbiosis. Academic press.

Stefan, G., Cornelia, B., Jorg, R., \& Michael, B. (2014). Soil water availability strongly alters the community composition of soil protists. Pedobiologia , 57 (4-6), 205-213.

Talukder, B., Ganguli, N., Matthew, R., van Loon, G. W., Hipel, K. W., \& Orbinski, J. (2021). Climate Change-Triggered Land Degradation and Planetary Health: A Review. Land Degradation 86 Development .

Toljander, J. F., Eberhardt, U., Toljander, Y. K., Paul, L. R., \& Taylor, A. F. (2006). Species composition of an ectomycorrhizal fungal community along a local nutrient gradient in a boreal forest. New Phytologist , 170 (4), 873-884.

van der Wal, A., Geydan, T. D., Kuyper, T. W., \& De Boer, W. (2013). A thready affair: linking fungal diversity and community dynamics to terrestrial decomposition processes. FEMS Microbiology Reviews, $37(4), 477-494$.

Waldrop, M. P., Zak, D. R., Blackwood, C. B., Curtis, C. D., \& Tilman, D. (2006). Resource availability controls fungal diversity across a plant diversity gradient. Ecology Letters , 9 (10), 1127-1135.

Wang, J., Bao, J., Su, J., Li, X., Chen, G., \& Ma, X. (2015). Impact of inorganic nitrogen additions on microbes in biological soil crusts. Soil Biology and Biochemistry , 88 , 303-313.

Wang, K., Zhang, C., Chen, H., Yue, Y., Zhang, W., Zhang, M., Qi, X., \& Fu, Z. (2019). Karst landscapes of China: patterns, ecosystem processes and services. Landscape Ecology , 34 (12), 2743-2763.

Wang, R., Wang, Y., Zheng, W., Hou, F., Hu, Y., \& Guo, S. (2021). Converting croplands to orchards changes soil microbial community composition and co-occurrence patterns. Land Degradation 8 S Development , 32 (8), 2509-2519.

Wang, S. J., Liu, Q. M., \& Zhang, D. F. (2004). Karst rocky desertification in southwestern China: geomorphology, landuse, impact and rehabilitation. Land Degradation 85 Development, 15 (2), 115-121.

Wen, L., Li, D., Yang, L., Luo, P., Chen, H., Xiao, K., Song, T., Zhang, W., He, X., Chen, H., \& Wang, K. (2016). Rapid recuperation of soil nitrogen following agricultural abandonment in a karst area, southwest China. Biogeochemistry, 129 (3), 341-354.

Wiesmeier, M., Urbanski, L., Hobley, E., Lang, B., von Lutzow, M., Marin-Spiotta, E., .. . \& Kogel-Knabner, I. (2019). Soil organic carbon storage as a key function of soils-A review of drivers and indicators at various scales. Geoderma , 333 , 149-162.

Xiao, D., Che, R., Liu, X., Tan, Y., Yang, R., Zhang, W., He, X., Xu, Z., \& Wang, K. (2019). Arbuscular mycorrhizal fungi abundance was sensitive to nitrogen addition but diversity was sensitive to phosphorus addition in karst ecosystems. Biology and Fertility of Soils , 55 (5), 457-469.

Xiao, D., Liu, X., Yang, R., Tan, Y., Zhang, W., He, X., Xu, Z., \& Wang, K. (2020). Nitrogen fertilizer and Amorpha fruticosaleguminous shrub diversely affect the diazotroph communities in an artificial forage grassland. Science of The Total Environment, 711 , 134967.

Xiao, W., Feng, S., Liu, Z., Su, Y., Zhang, Y., \& He, X. (2017). Interactions of soil particulate organic matter chemistry and microbial community composition mediating carbon mineralization in karst soils. Soil Biology and Biochemistry , 107 , 85-93.

Xu, E., \& Zhang, H. (2020). Human-desertification coupling relationship in the karst region. Land Degradation $\&$ Development .

Yang, W., Guo, Y., Wang, X., Chen, C., Hu, Y., Cheng, L., Gu, S., \& Xu, X. (2017). Temporal variations of soil microbial community under compost addition in black soil of Northeast China. Applied Soil Ecology , 121, 214-222. 
Zeilinger, S., Gupta, V.K., Dahms, T.E., Silva, R.N., Singh, H.B., Upadhyay, R.S., Gomes, E.V., Tsui, C.K.M., \& Nayak S, C. (2016). Friends or foes? Emerging insights from fungal interactions with plants.FEMS Microbiology Reviews , 40 (2), 182-207.

Zhang, W., Chen, H. S., Su, Y. R., Wang, K. L., Lin, H. F., \& Liu, K. P. (2013). Effects of reclamation and fertilization on calcareous soil fertility in the initial period of cultivation. Chinese Journal of Soil Science , 44 (4), 925-930.

Zhao, Z., Wei, X., Wang, X., Ma, T., Huang, L., Gao, H., Fan, J., Li, X., \& Jia, X. (2019a). Concentration and mineralization of organic carbon in forest soils along a climatic gradient. Forest Ecology and Management , $432,246-255$.

Zhao, Z.B., He, J.Z., Geisen, S., Han, L.L., Wang, J.T., Shen, J.P., Wei, W.X., Fang, Y.T., Li, P.P., \& Zhang, L.M. (2019b). Protist communities are more sensitive to nitrogen fertilization than other microorganisms in diverse agricultural soils. Microbiome , 7 (1), 1-16.

Zhou, J., Xue, K., Xie, J., Deng, Y., Wu, L., Cheng, X., Fei, S., Deng, S., He, Z., Van Nostrand, J.D., \& Luo, Y. (2012). Microbial mediation of carbon-cycle feedbacks to climate warming. Nature Climate Change , $2(2), 106-110$.

\section{Hosted file}

Tables.doc available at https://authorea.com/users/437857/articles/539209-key-bacterialfungal-and-protist-taxa-regulate-nutrient-availability-during-vegetation-restorationunder-different-climate-conditions-in-karst-soil

\section{Hosted file}

Figures.docx available at https://authorea.com/users/437857/articles/539209-key-bacterialfungal-and-protist-taxa-regulate-nutrient-availability-during-vegetation-restorationunder-different-climate-conditions-in-karst-soil

\section{Hosted file}

Graphical abstract.doc available at https://authorea.com/users/437857/articles/539209-keybacterial-fungal-and-protist-taxa-regulate-nutrient-availability-during-vegetationrestoration-under-different-climate-conditions-in-karst-soil

\section{Hosted file}

Highlights.doc available at https://authorea.com/users/437857/articles/539209-key-bacterialfungal-and-protist-taxa-regulate-nutrient-availability-during-vegetation-restorationunder-different-climate-conditions-in-karst-soil 